\title{
Review \\ Clinical review: Goal-directed therapy in high risk surgical patients
}

\author{
Nicholas Lees, Mark Hamilton and Andrew Rhodes \\ Department of Intensive Care Medicine, St George's Healthcare NHS Trust, Blackshaw Road, London SW17 0QT, UK
}

Corresponding author: Andrew Rhodes, andyr@sgul.ac.uk

Published: 26 October 2009

This article is online at http://ccforum.com/content/13/5/231

(c) 2009 BioMed Central Ltd
Critical Care 2009, 13:231 (doi:10.1186/cc8039)

\begin{abstract}
A small group of patients account for the majority of peri-operative morbidity and mortality. These 'high-risk' patients have a poor outcome due to their inability to meet the oxygen transport demands imposed on them by the nature of the surgical response during the peri-operative period. It has been shown that by targeting specific haemodynamic and oxygen transport goals at any point during the peri-operative period, the outcomes of these patients can be improved. This goal directed therapy includes the use of fluid loading and inotropes, in order to optimize the preload, contractility and afterload of the heart whilst maintaining an adequate coronary perfusion pressure. Despite the benefits seen, it remains a challenge to implement this management due to difficulties in identifying these patients, scepticism and lack of critical care resources.
\end{abstract}

\section{Oxygen delivery and hypoxia}

Oxygen is the substrate mitochondria require for aerobic metabolism. As oxygen is not stored, a constant supply is required. One of the main functions of the cardiovascular system is, in part, to supply tissues with oxygen. This supply must match any changing metabolic demands, otherwise inflammation and organ dysfunction may occur. Global oxygen delivery, $\mathrm{DO}_{2}$, is the total amount of oxygen delivered to tissues per minute and is described by the equation:

$$
\begin{gathered}
\mathrm{DO}_{2}(\mathrm{ml} / \mathrm{minute})=\text { Cardiac output }(\mathrm{CO})(\mathrm{L} / \text { minute }) \times \\
\text { arterial oxygen content }\left(\mathrm{CaO}_{2}\right)
\end{gathered}
$$

At rest and in health $\mathrm{DO}_{2}$ exceeds the oxygen consumption of all tissues $\left(\mathrm{VO}_{2}\right)$ combined. The oxygen extraction ratio (OER) is organ specific and is the ratio of $\mathrm{VO}_{2}$ to $\mathrm{DO}_{2}$. With moderate reductions in $\mathrm{DO}_{2}$, OER will increase, thereby maintaining aerobic metabolism. OER will keep increasing up to a critical $\mathrm{DO}_{2}$ below which $\mathrm{VO}_{2}$ becomes supply dependent and anaerobic metabolism will occur [1]. In critical illness the ability of tissues to increase OER is less efficient, making this more likely. The optimal level of $\mathrm{DO}_{2}$ varies according to metabolic demands but an inadequate $\mathrm{DO}_{2}$ is suggested if OER is very high, as demonstrated by mixed venous oxygen saturations $\left(\mathrm{SvO}_{2}\right)$ of $<70 \%$.

The consequences of tissue hypoxia are complicated and far reaching [2]. These include the activation of the endothelium through reduced levels of cyclic nucleotides 3',5'-adenosine monophosphate (cAMP) and 3'5'-guanosine monophosphate (cGMP). Vascular permeability is increased due to a disruption in the barrier function, leading to capillary leak and tissue oedema. Pro-inflammatory cytokines such as interleukins 1 and 8 are released. The endothelium becomes pro-coagulant and more adhesive to leukocytes. Vascular tone is increased, causing vasoconstriction. Leukocyte activation and activation of the complement cascade lead to inflammation. If this process of inflammation and microcirculatory failure is left unabated, then organ dysfunction may occur and this may ultimately lead to death. The detection and prevention of tissue hypoxia is therefore crucial.

\section{The high-risk surgical patient}

There are around three million surgical procedures performed each year in the United Kingdom. Mortality within 30 days of surgery is estimated to be between $0.7 \%$ and $1.7 \%$ [3]. Recent data from two large healthcare databases in the United Kingdom of over four million surgical procedures have demonstrated that a small group of patients account for more than $80 \%$ of deaths, but only $12.5 \%$ of surgical procedures [4]. These patients were undergoing high-risk surgery, with an expected mortality of greater than 5\%. There has been considerable interest in ways of identifying these patients as

$\mathrm{CaO}_{2}=$ arterial oxygen content; $\mathrm{Cl}=$ cardiac index; $\mathrm{CO}=$ cardiac output; $\mathrm{DO}_{2}=$ global oxygen delivery; $\mathrm{DO} /=$ oxygen delivery index; $\mathrm{FTC}_{2}=$ corrected flow time; GDT = goal directed therapy; MET = metabolic equivalent; OER = oxygen extraction ratio; PAC = pulmonary artery catheter; RCT = randomised controlled trial; $\mathrm{ScvO}_{2}=$ central venous oxygen saturation; $\mathrm{SvO}_{2}=$ mixed venous oxygen saturation; VO $2=$ tissue oxygen consumption; $\mathrm{VO}_{2} \mathrm{I}=$ tissue oxygen consumption index. 
well as strategies to reduce their disproportionately high mortality.

Surgical patients can be described as high-risk based on surgical or patient-related factors [5]. High-risk surgery relates to the extent, invasiveness or complexity of the procedure, such as vascular surgery, extensive surgery for carcinoma, intra-abdominal surgery for peritoneal soiling, multiple-cavity trauma surgery, emergency surgery and, to a lesser degree, surgery of long duration. All of these factors are associated with an increase in the stress response to the surgical insult, an increase in the oxygen demand and an increased rate of complications and death [6]. It has been known for many years that surgical patients are more likely to suffer complications or die if they have limited physiological reserve [7]. It has been suggested that it is the inability to meet this increased oxygen demand that causes the patients to do badly. It has been shown that non-survivors after major surgery have lower levels of oxygen consumption than survivors and, furthermore, that the magnitude and duration of this relative 'oxygen debt', indicating tissue hypoxia, were related to worse outcomes [8,9]. Physiologically fitter patients are able to meet this increased oxygen demand by increasing their oxygen delivery, mainly through increases in cardiac output. Poor cardiopulmonary reserve limits the patient's ability to respond to the stressful insult and prevents the body compensating for this increased oxygen demand and, in essence, defines the 'high-risk surgical patient.'

\section{Identifying the high-risk surgical patient}

Identification of the high-risk patient has implications on management throughout the peri-operative period. Defining high risk can be subjective and a variety of screening tests and scores have been used. It has been suggested that a patient with an individual mortality risk of greater than $5 \%$ or undergoing a procedure carrying a $5 \%$ mortality be defined as a high-risk surgical patient [10]. In terms of overall risk, relatively simple clinical criteria can be used to identify a highrisk patient (Table 1). Similarly, the P-POSSUM score (Portsmouth Physiologic and Operative Severity Score enUmeration of Mortality) could be used [11]. Pre-operative risk may be more objectively stratified by the American Society of Anesthesiologists (ASA) score [12]. Goldman and colleagues [13], Detsky and colleagues [14] and, more recently, Lee and colleagues [15] have also described established means of assessing cardiac risk. In 2007 the American College of Cardiology/American Heart Association published guidelines designed to help in the identification and pre-operative management of cardiac risk for patients undergoing non-cardiac surgery [16]. There are many investigations for cardiac and respiratory disease, such as stress echocardiography, but despite identifying myocardial ischaemia, most are poor as single pre-operative screening tests with low positive predictive value for post-operative events [5]. For a functional assessment of risk, the American College of Cardiology/American Heart Association guidelines
Table 1

\section{Clinical criteria for high-risk surgical patients [38]}

1 Severe cardiac or respiratory illness resulting in severe functional limitation

2 Extensive surgery planned for carcinoma involving bowel anastamosis

3 Acute massive blood loss ( $>2.5$ litres)

4 Aged over 70 years with moderate functional limitation of one or more organ systems

5 Septicaemia (positive blood cultures or septic focus)

6 Respiratory failure $\left(\mathrm{PaO}_{2}<8 \mathrm{kPa}\right.$ on $\mathrm{FiO}_{2}>0.4$, that is, $\mathrm{PaO}_{2}: \mathrm{FiO}_{2}$ ratio $<20 \mathrm{kPa}$ or ventilation $>48$ hours)

7 Acute abdominal catastrophe (for example, pancreatitis, perforated viscous, gastro-intestinal bleed)

8 Acute renal failure (urea $>20 \mathrm{mmol} \mathrm{I}^{-1}$, creatinine $>260 \mu \mathrm{mol} \mathrm{l-1}$ )

9 Surgery for abdominal aortic aneurysm

$\mathrm{PaO}_{2}$, arterial partial pressure of oxygen; $\mathrm{FiO}_{2}$; fractional inspired concentration of oxygen.

describe estimation of METS (metabolic equivalents; Duke Activity Status Index [17]), with one MET representing adult resting oxygen consumption $\left(\mathrm{VO}_{2}\right)$ and four METS or less representing poor cardiorespiratory function and, therefore, high risk. For an objective assessment of cardiopulmonary function and subsequent risk stratification, the best validated method has been cardiopulmonary exercise testing and assessment of anaerobic threshold [18]. Older and colleagues showed that cardiopulmonary exercise testing was able to identify the high-risk surgical patient and allowed appropriate selection of peri-operative management (ward, high dependency or ICU). Identification of a group of patients with anaerobic thresholds of $<11 \mathrm{ml} / \mathrm{kg} /$ minute and evidence of myocardial ischaemia led to pre-admission to intensive care and a reduction in mortality in this group from $18 \%$ to $8.9 \%$. This threshold and the presence of inducible myocardial ischaemia were predictive of post-operative survival; almost all patients who died post-operatively had anaerobic thresholds of less than $11 \mathrm{ml} / \mathrm{kg} /$ minute [5].

\section{Goal-directed therapy Background}

Major surgery is associated with a significant systemic inflammatory response and this in itself is associated with an increase in oxygen demand. In health, $\mathrm{DO}_{2}$ is augmented by increasing $\mathrm{CO}$ and tissue oxygen extraction. If a patient is unable to achieve this due to cardiopulmonary disease, then there will be a degree of tissue dysoxia, which in the face of increased metabolic demand can lead to cellular dysfunction and ultimately organ dysfunction, failure and death. Complications and death following surgery have been shown to be associated with reduced $\mathrm{DO}_{2}$ and $\mathrm{VO}_{2}$ or a surrogate, the central venous oxygen saturation $\left(\mathrm{ScvO}_{2}\right) \quad[19,20]$. Reduced perfusion of the gut has also been implicated in 
post-operative organ dysfunction, due to disruption of the gut endothelial barrier with leakage of endotoxin into the circulation, activating multiple inflammatory pathways [21]. From the equation above, increasing $\mathrm{DO}_{2}$ is achieved by increasing $\mathrm{CO}$ and/or $\mathrm{CaO}_{2}$. As dissolved oxygen is small, $\mathrm{CaO}_{2}$ is increased by increasing the arterial oxygen saturation and/or the haemoglobin concentration. This should occur as a matter of course in intensive care. $\mathrm{CO}$ is therefore the variable that is most readily manipulated in order to increase $\mathrm{DO}_{2}$, and this is usually performed using fluids and inotropes to improve blood flow. It is worth mentioning that $\mathrm{DO}_{2}$ commonly measured is a global measurement whereas it is probable that regional, organ-specific or microcirculatory areas are the ones with compromised oxygenation. Nevertheless, it has been shown repeatedly that augmenting global $\mathrm{DO}_{2}$ is beneficial $[8,9,22]$.

\section{Evidence for goal directed therapy}

There is considerable evidence to demonstrate the benefits of augmenting oxygen delivery in high-risk surgical patients during the peri-operative period [23]. In 1988 Shoemaker and colleagues [8] showed that morbidity and mortality of high-risk patients, a population that had a mortality of 30 to $40 \%$ following surgery, could be significantly reduced by using goal directed therapy (GDT) to meet the increased metabolic requirements following surgery. Therapeutic targets were based on physiological values that they had themselves observed in survivors after surgery [22,24-26]. These perfusion-related targets included cardiac index $(\mathrm{Cl})$, $\mathrm{DO}_{2}$ and $\mathrm{VO}_{2}$. In the early studies these variables and the associated therapy were monitored and guided with a pulmonary artery catheter (PAC) with targets of $\mathrm{Cl}$ $>4.5 \mathrm{l} / \mathrm{minute} / \mathrm{m}^{2}$, oxygen delivery index $\left(\mathrm{DO}_{2} \mathrm{l}\right)$ $>600 \mathrm{ml} / \mathrm{minute} / \mathrm{m}^{2}$ and $\mathrm{VO}_{2} \mathrm{I}>170 \mathrm{ml} /$ minute $/ \mathrm{m}^{2}$. With this approach the mortality was substantially reduced in comparison to standard care using commonly measured parameters such as heart rate, arterial blood pressure and central venous pressure. This led to the concept that this group of patients could be optimised to so-called 'supranormal' values compared to resting values in the perioperative period in order to improve their outcome. In 1993 Boyd and colleagues [27] conducted a randomised controlled trial (RCT) in which the same treatment goals were targeted pre- and post-operatively by means of supplemental oxygen, fluid and blood products. A 75\% reduction in mortality was shown together with less post-operative complications. Wilson and colleagues [28], again targeting $\mathrm{DO}_{2} \mathrm{l}>600 \mathrm{ml} / \mathrm{minute} / \mathrm{m}^{2}$, but also a haemoglobin of $\geq 11 \mathrm{~g} / \mathrm{dl}$ and pulmonary artery occlusion pressure $\geq 12 \mathrm{mmHg}$, subsequently confirmed that preoperative optimisation of oxygen delivery significantly reduced hospital mortality with fewer complications and reduced length of stay. Other groups have reported similar favourable results in cardiac surgical patients [29], general surgical patients [30] and trauma patients [31]. It has also been demonstrated that goal-directed administration of intravenous fluid improves gut perfusion and reduces major complications [30,31]. Donati and colleagues [32] conducted a prospective RCT of 135 high-risk surgical patients scheduled for major abdominal surgery and found a significantly lower length of hospital stay and number of organ failures in patients randomised to receive GDT starting intra-operatively and in whom the OER was maintained at $<27 \%$. The finding that peri-operative augmentation of $\mathrm{DO}_{2}$ through GDT is associated with improved outcome has now been demonstrated in a number of meta-analyses by Kern and Shoemaker [33], Boyd [34] and more recently by Poeze and colleagues [35] and the Cochrane group [36]. What is clear is that pre-optimisation before and during surgery [26-28,30,37] and post-optimisation in ICU [38] in a protocolised GDT manner improves patient outcomes in high-risk surgical patients (Figure 1).

\section{Controversy}

Despite these promising results, this practice has not been widely embraced for a number of reasons. Firstly, there may be confusion in identifying patients who may benefit from this therapy. Secondly, all the initial trials utilized the PAC. When this technique ran into controversy [39], the therapies associated with it were also debated. Even though there are now many alternatives, the concept of GDT is still considered to be synonymous with the PAC. Furthermore, there is some conflicting evidence. The largest and perhaps most controversial trial to date purporting to provide GDT for surgical patients was published by Sandham and co-workers $[40,41]$. Despite this controversy, the meta-analysis, even when including all available studies, confirms an improvement in mortality [36].

There has also been confusion inadvertently extrapolating results from other trials providing GDT to different patient groups. For instance, Gattinoni and colleagues [42] demonstrated that aggressive GDT is not effective for patients once organ failure is established in the critically ill. Hayes and colleagues demonstrated a worse outcome [43], although this study involved very high levels of dobutamine that would not nowadays be considered reasonable to meet these goals. Benefit has not been seen in patients who are not considered as high-risk [29], or if supranormal $\mathrm{DO}_{2}$ targets were not used $[44,45]$. Individual variations of critical oxygen delivery or anaerobic thresholds may be a major reason for the heterogeneity of some of these studies and patient populations.

A major and more realistic limitation to the adoption of GDT is that of limited critical care resources. Many units are unable to admit high-risk patients pre-operatively to institute GDT and, similarly, many high-risk patients do not return to a critical care environment following surgery. Currently, only a small proportion (fewer than 15\%) of high-risk patients are admitted to intensive care [4]. Numerous trials have shown that length of hospital stay and complications can be reduced by instituting GDT. As critical care resources are slowly expanding, it can be argued that it is not only better for the 
Figure 1

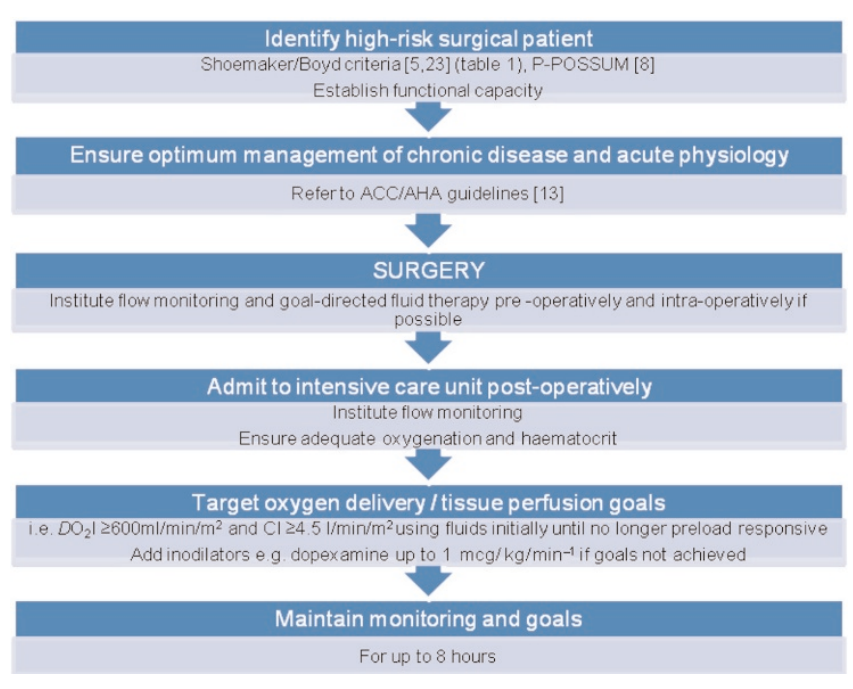

Suggested algorithm for the provision of goal directed therapy to high risk surgical patients. ACC/AHA, American College of Cardiology/American Heart Association; $\mathrm{Cl}$, cardiac index; $\mathrm{DO}_{2} \mathrm{l}$, oxygen delivery index.

patient but also economically sound to justify this. Encouragingly, it has been shown that it is possible to select patients who would most likely benefit from pre-operative intensive care admission based on high-risk criteria [46]. Pearse and colleagues [38] showed that initiation of GDT post-operatively and after ICU admission confers significant benefit, which is reassuring considering the potential difficulties of implementing it pre- or peri-operatively. Paradoxically, nearly all of the studies that have assessed GDT have demonstrated a reduced incidence of complications following surgery with a subsequent decreased need for critical care services. It will take a paradigm shift in many clinicians (and their managers) thinking though to convert a rationale of reacting to problems to one of preventing them happening in the first place, even though this may reduce the overall demand for this expensive resource.

\section{Which goals to use?}

The concept of targeting a specific goal is not new and is done every day in intensive care, be it mean arterial pressure, arterial blood gases or haemoglobin. Several authors have demonstrated that the standard parameters of heart rate, blood pressure, central venous pressure and urine output are neither predictive nor able to be routinely manipulated to improve outcome. Indeed, a recent meta-analysis has proven that the central venous pressure is not able to identify which patients require more fluid [47]. Although manipulating haemodynamics is certainly beneficial using goals of stroke volume and/or $\mathrm{Cl}$, if one accepts the concept of avoiding tissue oxygen debt in high-risk surgical patients, then the most important parameters that are associated with improved survival relate to oxygen flux. The most commonly used oxygen transport goals have been $\mathrm{DO}_{2} \mathrm{I}$ and tissue oxygen consumption index $\left(\mathrm{VO}_{2} \mathrm{l}\right)$. GDT traditionally has been associated with targeting the $\mathrm{DO}_{2} \mathrm{I}$ to a supranormal value of $>600 \mathrm{ml} / \mathrm{minute} / \mathrm{m}^{2}$. Although this is perhaps the best studied endpoint for the resuscitation, it is by no means clear that it is the 'best' marker; rather, it is the only level of $\mathrm{DO}_{2}$ that has been repeatedly studied. Others may yet prove to be better still. The use of supranormal goals, although controversial, has been shown in many studies to be beneficial since Shoemaker and colleagues' original work. Donati and colleagues [32] used OER, aiming for a goal of $<27 \%$ (shown to be a predictor of survival in high risk surgical patients [22]), using fluids and dobutamine. The OER is based on arterial and central venous saturation measurements and flow monitoring was not required in their study. In the intra-operative setting, where $\mathrm{DO}_{2}$ is less easy to measure and target, a variety of other goals have been used. These include the corrected flow time (FTc) from the oesophageal Doppler trace (for example, targeting $>0.35 \mathrm{~s}$ [48]) or pulse pressure variation. Other goals studied that may be useful include serum lactate and mixed venous saturations $\left(\mathrm{SvO}_{2}\right)$ [29]. Regional measures of $\mathrm{DO}_{2}$ such as gastric intramucosal $\mathrm{pH}(\mathrm{pHi})$ [49] and near infrared spectroscopy (NIRS) are promising but have not been formally evaluated in a GDT manner.

\section{How to perform goal directed therapy in high- risk surgical patients \\ Monitoring}

The first and most common step in GDT is to ensure that the circulating volume is at an optimal level. The identification of the ideal preload, or patients who are likely to respond to a fluid challenge (preload responsiveness), has been extensively studied. It is quite clear that none of the traditional parameters are useful to accurately detect the volaemic status of patients. In order to overcome this problem, all studies have utilized some sort of blood flow monitoring and various different technologies have been used to measure cardiac output or stroke volume. Most of the earlier work was using the PAC, but with the advancement of technology this can now be done with less invasive techniques. Many subsequent studies have involved a single proprietary flow monitoring device. Current flow monitoring techniques that are used include Doppler technologies or arterial pressure waveform analysis, thereby measuring changes in stroke volume or cardiac output. These can be used either to predict a patient likely to respond to a volume challenge or to carefully monitor the response to a fluid bolus. This therefore provides a sophisticated and sensitive mechanism for titrating intravenous fluids to complex patients. Benefit has been demonstrated with fluid loading alone to maximize stroke volume, using these technologies [48,50]. Targeting of the pulse pressure variation in mechanically ventilated patients to a value of less than $10 \%$ with fluid challenges has been demonstrated to improve post-operative outcome and reduce length of hospital stay [51]. 
Fluid therapy as guided by the oesophageal Doppler (Deltex Medical Ltd, Chichester, UK) reduces mortality and hospital stay $[31,52,53]$. The oesophageal Doppler is well tolerated and can be used throughout the entire peri-operative period. It has little bias and high clinical agreement when compared with the PAC for monitoring changes in cardiac output [54]. FTc is inversely proportional to systemic vascular resistance and is sensitive to changes in left ventricular preload [55]. It may also be a more sensitive indicator of cardiac filling than pulmonary artery occlusion pressure [56]. Improved outcome as demonstrated by faster return of gastrointestinal function, a reduction in post-operative complications and shortened hospital stay was demonstrated when using the oesophageal Doppler for goal-directed fluid administration (that is, targeting stroke volume and $\mathrm{FTc}$ to maximize $\mathrm{Cl}$ ) during major surgery [48]. A meta-analysis of five RCTs of 420 patients undergoing major abdominal surgery showed fewer complications, less requirement for inotropes, faster return of gastro-intestinal function, fewer ICU admissions and shorter hospital stay in patients who received oesophageal Dopplerguided haemodynamic management [50].

The LiDCOplus system (LiDCO Ltd, Cambridge, UK) is also well validated [57]. In 2005 Pearse and colleagues [38] conducted a RCT of post-operative GDT in high-risk general surgical patients using colloid and dopexamine to achieve a $\mathrm{DO}_{2} \mathrm{I}$ of $600 \mathrm{ml} / \mathrm{minute} / \mathrm{m}^{2}$ or conventional management using the LiDCOplus to measure CO. There were fewer complications in the control group (44\% versus $68 \%$ ), less complications per patient and a shorter hospital stay, although there was no difference in 28- or 60-day mortality.

Several studies have shown that the PiCCO system (PULSION Medical Systems, Munich, Germany) is also a reliable method of assessing cardiac preload and may actually be more sensitive than the PAC [58-60]. Goepfert and colleagues [61] devised a GDT algorithm based on targeting global end-diastolic volume index, an indicator of cardiac preload as measured by PiCCO to achieve a goal of $>640 \mathrm{ml} / \mathrm{m}^{2}$ and $\mathrm{Cl}>2.5 \mathrm{l} /$ minute $/ \mathrm{m}^{2}$ in patients undergoing elective coronary artery bypass grafting surgery. This therapy was instituted immediately after induction of anaesthesia and continued in the ICU post-operatively. These patients benefited from reduced vasopressor and inotrope requirement, reduced duration of mechanical ventilation and were ready for ICU discharge earlier than the control group [61].

The Flotrac (Edwards, Irving, USA) is a blood flow sensor needing no calibration that attaches to the patient's existing arterial line and, in conjunction with the processing and display unit (Vigileo monitor), provides non-invasive cardiac output monitoring that derives its values from the arterial blood pressure signal. Comparisons with other reference techniques have been inconsistent and, to date, it remains untested in a GDT algorithm [37].

\section{How to achieve the goals}

The aim of GDT is to prevent tissue oxygen debt by maintaining tissue perfusion. Many studies have tried to achieve this by augmenting $\mathrm{DO}_{2}$. $\mathrm{CO}$ should be optimised in reference to preload, afterload, contractility and stroke volume whilst maintaining an adequate coronary perfusion pressure. There is an optimal haematocrit that is sufficient for oxygen transport but does not compromise rheology and, in general, haemoglobin should be kept above $7 \mathrm{~g} / \mathrm{dl}$ (aiming higher in patients with ischaemic heart disease) [62]. In all studies patients have been kept well oxygenated and there is some evidence that the use of continuous positive airways pressure in the post-operative period is beneficial [63]. Fluid boluses alone may be sufficient to achieve goals of $\mathrm{CO}$ and $\mathrm{DO}_{2}$, and GDT using just fluids has been shown to improve outcome in certain groups of surgical patients $[31,48,49]$. Often fluids may not be sufficient to achieve these goals and, in addition, a positive inotrope or vasodilator is necessary. Lobo and co-workers [64] compared the use of fluids and dobutamine or fluids alone to achieve the goal of $\mathrm{DO}_{2} \mathrm{I}$ $>600 \mathrm{ml} / \mathrm{minute} / \mathrm{m}^{2}$ in high-risk surgical patients. The use of fluid and dobutamine conferred better post-operative outcomes with less cardiovascular complications than the fluid alone group. Those patients given dobutamine were more likely to achieve the goals. Dobutamine is also a positive inotrope and peripheral vasodilator. Dopexamine is a dopamine analogue with actions at beta adrenoreceptors and also at peripheral dopamine receptors. It is a positive inotrope and peripheral vasodilator that improves microcirculatory flow and splanchnic perfusion and oxygenation, which may reduce inflammation secondary to the tissue hypoxia and translocation of bacterial products or endotoxin. This is probably the most extensively studied drug in this setting and a recent meta-analysis has demonstrated it to be of considerable use, with low-dose infusion ( $\leq 1 \mu \mathrm{g} / \mathrm{kg} /$ minute) associated with survival benefit and reduction in hospital stay. A survival benefit has not been seen with doses higher than this [65]. Wilson compared dopexamine and adrenaline and found that although an adequate $\mathrm{DO}_{2}$ was achieved with adrenaline, only dopexamine conferred a reduction in morbidity and length of hospital stay [28]. Evidence shows that the use of dobutamine or dopexamine confers significant benefits in GDT. These drugs should be used with caution in patients with a high risk of peri-operative ischaemic cardiovascular events where excessive beta stimulation may be undesirable. Such patients have usually been excluded from GDT studies.

\section{Suggested strategy for GDT}

Once a high-risk patient is identified, any acute organ dysfunction or physiological abnormality should be managed as usual. Optimal control of any chronic illness should be ensured. This includes severe and active ischaemic heart disease, which should mandate appropriate medical treatment prior to surgery. GDT should be started as soon as possible before or after surgery as resources allow. Adequate oxygenation and haematocrit should be ensured. A variety of 
metabolic endpoints are surrogate flow measurements, such as lactate, $\mathrm{SvO}_{2}, \mathrm{ScvO}_{2}$, which may be useful during resuscitation, but $\mathrm{CO}\left(\mathrm{Cl} 4.5 \mathrm{l} / \mathrm{minute} / \mathrm{m}^{2}\right)$ and oxygen transport goals are important $\left(\mathrm{DO}_{2} \mathrm{l} \geq 600 \mathrm{ml} / \mathrm{minute} / \mathrm{m}^{2}\right)$ so direct flow monitoring should be implemented. Fluids should be given to increase $\mathrm{CO}$ and inodilators such as dopexamine and dobutamine added once the patient is no longer fluid (preload) responsive or not achieving the goals. Evidence suggests that GDT should continue for 8 hours [38], although many intra-operative studies show benefit with much shorter time courses.

\section{Conclusion}

Most peri-operative deaths are over-represented by a population of patients that can be described as high-risk who have insufficient physiological reserve to meet the demands of major surgery. Identification of these patients pre-operatively based on patient and/or surgical criteria or by formal dynamic testing of functional capacity is desirable and possible. Assessment and augmentation of global oxygen delivery can improve outcome in critically ill patients. Maintaining an adequate oxygen flux in tissues is crucial for health and ensuring tissue perfusion is the key to GDT. Despite a general lack of implementation, there is considerable evidence to show that GDT in selected patients using blood flow monitoring to achieve supranormal oxygen delivery targets to increase tissue perfusion and oxygenation decreases morbidity and mortality. Starting GDT at any time during the peri-operative period has shown benefit. Studies of GDT have involved a variety of different techniques to measure and achieve goals that have also varied, although the favourable outcomes seen form a strong case for admitting these patients to intensive care and increasing critical care resources.

\section{Competing interests}

AR has received lecture fees from LiDCO and consulting fees from Cheetah Medical and Edwards Lifesciences. $\mathrm{MH}$ has received lecturing fees from Dletex andf Edwards Lifesciences. NL declares no conflict of interest.

\section{References}

1. Leach RM, Treacher DF: Oxygen transport: relation between oxygen delivery and consumption. The pulmonary physician in critical care. Thorax 1992, 47:971-978.

2. Karimova AK, Pinsky DJ: The endothelial response to oxygen deprivation: biology and clinical implications. Intensive Care Med 2001, 27:19-31.

3. Cullinane M, Gray AJG, Hargraves CMK, Lansdown M, Martin IC, Schubert M: The 2003 report of the National Confidential Inquiry into Peri-operative Deaths. http://www.ncepod.org.uk/ pdf/2003/03full.pdf [accessed 16 October 2009]

4. Pearse RM, Harrison DA, James P, Watson D, Hinds C, Rhodes A, Grounds RM, Bennett ED: Identification of the high risk surgical population in the United Kingdom. Crit Care 2006, 10:R81.

5. Older $\mathrm{P}, \mathrm{Hall} \mathrm{A}$ : Clinical review: how to identify high-risk surgical patients. Crit Care 2004, 8:369-372.

6. Waxman K, Shoemaker WC: Management of postoperative and posttraumatic respiratory failure in the intensive care unit. Surg Clin N Am 1980, 60:1413-1428.

7. Boyd AR, Tremblay RE, Spencer FC, Bahnson HT: Estimation of cardiac output soon after cardiac surgery with cardiopulmonary bypass. Ann Surg 1959, 150:613-625.

8. Shoemaker WC, Appel PL, Kram HB, Waxman K, Lee TS: Prospective trial of supranormal values of survivors as therapeutic goals in high-risk surgical patients. Chest 1988, 94: 1176-1186.

9. Shoemaker WC, Appel PL, Kram HB: Hemodynamic and oxygen transport responses in survivors and nonsurvivors of high-risk surgery [see comment]. Crit Care Med 1993 21:977990.

10. Boyd $\mathrm{O}$, Jackson $\mathrm{N}$ : Clinical review: How is risk defined in high-risk surgical patient management? Crit Care 2005, 9: 390-396.

11. Prytherch DR, Whiteley MS, Higgins B, Weaver PC, Prout WG, Powell SJ: POSSUM and Portsmouth POSSUM for predicting mortality. Physiological and Operative Severity Score for the enUmeration of Mortality and morbidity. $\mathrm{Br} J$ Surg 1998, 85: 1217-1220.

12. Wolters $U$, Wolf $T$, Stutzer $H$, Schroder $T$ : ASA classification and perioperative variables as predictors of postoperative outcome. Br J Anaesth 1996, 77:217-222.

13. Goldman L, Caldera DL, Nussbaum SR, Southwick FS, Krogstad D, Murray B, Burke DS, O'Malley TA, Goroll AH, Caplan CH, Nolan J, Carabello B, Slater EE: Multifactorial index of risk in noncardiac surgical procedures. N Engl J Med 1977, 297:845850.

14. Detsky AS, Abrams HB, Forbath N, Scott JG, Hilliard JR: Cardiac assessment for patients undergoing non-cardiac surgery. A multifactorial clinical risk index. Arch Intern Med 1986, 146: 2131-2134.

15. Lee TH, Marcantonio ER, Mangione CM, Thomas EJ, Polanczyk CA, Cook EF, Sugarbaker DJ, Donaldson MC, Poss R, Ho KK, Ludwig LE, Pedan A, Goldman L: Derivation and prospective validation of a simple index for prediction of cardiac risk of major noncardiac surgery. Circulation 1999, 100:1043-1049.

16. Fleisher LA, Beckman JA, Brown KA, Calkins H, Chaikof EL, Fleischmann KE, Freeman WK, Froehlich JB, Kasper EK, Kersten JR, Riegel B, Robb JF, Smith SC Jr, Jacobs AK, Adams CD, Anderson JL, Antman EM, Buller CE, Creager MA, Ettinger SM, Faxon DP, Fuster V, Halperin JL, Hiratzka LF, Hunt SA, Lytle BW, Nishimura R, Ornato JP, Page RL, Riegel B, et al:: ACC/AHA 2007 Guidelines on Perioperative Cardiovascular Evaluation and Care for Noncardiac Surgery: Executive Summary: A Report of the American College of Cardiology/American Heart Association Task Force on Practice Guidelines (Writing Committee to Revise the 2002 Guidelines on Perioperative Cardiovascular Evaluation for Noncardiac Surgery) Developed in Collaboration With the American Society of Echocardiography, American Society of Nuclear Cardiology, Heart Rhythm Society, Society of Cardiovascular Anesthesiologists, Society for Cardiovascular Angiography and Interventions, Society for Vascular Medicine and Biology, and Society for Vascular Surgery. J Am Coll Cardiol 2007, 50:e159-241.

17. Hlatky MA, Boineau RE, Higginbotham MB, Lee KL, Mark DB, Califf RM, Cobb FR, Pryor DB: A brief self-administered questionnaire to determine functional capacity (the Duke Activity Status Index). Am J Cardiol 1989, 64:651-654.

18. Older $\mathrm{P}, \mathrm{Hall} \mathrm{A}$, Hader R: Cardiopulmonary exercise testing as a screening test for perioperative management of major surgery in the elderly. Chest 1999, 116:355-362.

19. Pearse R, Dawson D, Fawcett J, Rhodes A, Grounds RM, Bennett ED: Changes in central venous saturation after major surgery, and association with outcome. Crit Care 2005, 9:R694-R699.

20. Shoemaker WC, Appel PL, Kram HB: Role of oxygen debt in the development of organ failure, sepsis and death in highrisk surgical patients. Chest 1992, 102:208-215.

21. Chieveley-Williams S, Hamilton-Davies C: The role of the gut in major surgical postoperative morbidity. Int Anesthesiol Clin 1999, 37:81-110.

22. Bland RD, Shoemaker WC, Abraham E, Cobo JC: Haemodynamic and oxygen transport patterns in surviving and nonsurviving patients. Crit Care Med 1985, 13:85-90.

23. Lugo G, Arizpe D, Dominguez G, Ramirez M, Tamariz O: Relationship between oxygen consumption and oxygen delivery during anesthesia in high-risk surgical patients. Crit Care Med 1993, 21:64-69.

24. Shoemaker WC, Montgomery ES Kaplan E Elwyn DH: Physio- 
logic patterns in surviving and nonsurviving shock patients. Arch Surg 1973, 106:630-636.

25. Bland RD, Shoemaker WC: Probability of survival as a prognostic and severity illness score in critically ill surgical patients. Crit Care Med 1985, 13:91-95.

26. Shoemaker WC, Appel PL, Bland R: Use of physiologic monitoring to predict outcome and to assist in clinical decisions in critically ill postoperative patients. Am J Surg 1983, 146:4350.

27. Boyd O, Grounds RM, Bennett ED: A randomized clinical trial of the effect of deliberate perioperative increase of oxygen delivery on mortality in high-risk surgical patients. JAMA 1993, 270:2699-2707.

28. Wilson J, Woods I, Fawcett J, Whall R, Dibb W, Morris C, McManus E: Reducing the risk of major elective surgery: randomised controlled trial of preoperative optimisation of oxygen delivery. BMJ 1999, 318:1099-1103.

29. Polonen P, Ruokonen E, Hippelainen M, Poyhonen M, Takala J: A prospective randomized study of goal orientated hemodynamic therapy in cardiac surgical patients. Anesthesia Analgesia 2000, 90:1052-1059.

30. Lobo SM, Salgado PF, Castillo VG, Borim AA, Polachini CA, Palchetti JC, Brienzi SL, de Oliveira GG: Effects of maximising oxygen delivery on morbidity and mortality in high-risk surgical patients. Crit Care Med 2000, 10:3396-3404.

31. Sinclair S, James S, Singer M: Intraoperative intravascular volume optimisation and length of hospital stay after repair of proximal femoral fracture: randomised controlled trial. BMJ 1997, 315:909-912.

32. Donati A, Loggi S, Preiser J-C, Orsetti G, Munch C, Gabbanelli V, Pelaia P, Pietropaoli P: Goal-directed intraoperative therapy reduces morbidity and length of hospital stay in high-risk surgical patients. Chest 2007, 132:1817-1824.

33. Kern JW, Pharm D, Shoemaker WC: Meta-analysis of hemodynamic optimization in high-risk patients. Crit Care Med 2002, 30:1686-1692

34. Boyd O: The high-risk surgical patient - where are we now? Clin Intensive Care 1999, 10:161-167.

35. Poeze M, Greve JWM, Ramsay G: Meta-analysis of hemodynamic optimization: relationship to methodological quality. Crit Care 2005, 9:R771-R779.

36. Grocott MPW, Hamilton MA, Bennett ED, Harrison D, Rowan K: Perioperative increase in global blood flow to explicit defined goals and outcomes following surgery (Cochrane Protocol). Cochrane Database Syst Rev 2006:Issue 2.

37. Kapoor PM, Kakani M, Chowdhury U, Choudhury M, Lakshmy R, Kiran U: Early goal-directed therapy in moderate to high-risk cardiac surgery patients. Ann Card Anaesth 2008, 11:27-34.

38. Pearse R, Dawson D, Fawcett J, Rhodes A, Grounds RM, Bennett ED: Early goal-directed therapy after major surgery reduces complications and duration of hospital stay. A randomised, controlled trial [ISRCTN38797445]. Crit Care 2005, 9:R687R693.

39. Connors AF Jr, Speroff T, Dawson NV, Thomas C, Harrell FE Jr, Wagner D, Desbiens N, Goldman L, Wu AW, Califf RM, Fulkerson WJ Jr, Vidaillet $\mathrm{H}$, Broste S, Bellamy P, Lynn J, Knaus WA: The effectiveness of right heart catheterization the initial care of critically ill patients. JAMA 1996, 276:889-897.

40. Sandham JD, Hull RD, Brant RF, Knox L, Pineo GF, Doig CJ, Laporta DP, Viner S, Passerini L, Devitt H, Kirby A, Jacka M; for the Canadian Critical Care Trials Group: A randomized controlled trial of the use of pulmonary artery catheters in highrisk surgical patients. N Engl J Med 2003, 348:5-14.

41. Harvey S, Young D, Brampton W, Cooper AB, Doig G, Sibbald W, Rowan K: Pulmonary artery catheters for adult patients in intensive care. Cochrane Database Syst Rev 2006, 3: CD003408.

42. Gattinoni L, Brazzi L, Pelosi P, Latini R, Tognoni G, Pesenti A, Fumagalli R: A trial of goal-orientated hemodynamic therapy in critically ill patients. N Engl J Med 1995, 333:1025-1036.

43. Hayes MA, Timmins AC, Yau EH, Palazzo M, Hinds CJ, Watson $D$ : Elevation of systemic oxygen delivery in the treatment of critically ill patients. N Engl J Med 1994, 330:1717-1723.

44. Ziegler DW, Wright JG, Choban PS, Flancbaum L: A prospective randomized trial of preoperative 'optimization' of cardiac function in patients undergoing elective peripheral vascularsurgery. Surgery 1997, 122:584-592.
45. Valentine RJ, Duke ML, Inman MH, Grayburn PA, Hagino RT,Kakish HB, Clagett GP: Effectiveness of pulmonary artery catheters in aortic surgery: a randomized trial. J Vasc Surg 1998, 27:203-211.

46. Curran JE, Grounds RM: Ward versus intensive care management of high-risk surgical patients. Br J Surg 1998, 85:956961.

47. Marik PE, Baram M, Vahid B: Does central venous pressure predict fluid responsiveness? A systematic review of the literature and the tale of seven mares. Chest 2008, 134:172-178.

48. Gan TJ, Soppitt A, Maroof M, El-Moalem H, Robertson KM, Moretti E, Dwane P, Glass PSA: Goal directed intraoperative fluid administration reduces length of hospital stay after major surgery. Anesthesiology 2002, 97:820-826.

49. Mythen MG, Webb A: Perioperative plasma volume expansion reduces the incidence of gut mucosal hypoperfusion during cardiac surgery. Arch Surg 1995, 130:423-429.

50. Abbas SM, Hill AG: Systematic review of the literature for the use of oesophageal Doppler monitor for fluid replacement in major abdominal surgery. Anaesthesia 2008, 63:44-51.

51. Lopes MR, Oliveira MA, Pereira VO, Lemos IP, Auler JOC, Michard F: Goal-directed fluid management based on pulse pressure variation monitoring during high-risk surgery: a pilot randomized controlled trial. Crit Care 2007, 11:R100.

52. Wakeling HG, McFall MR, Jenkins CS, Woods WG, Miles WF, Barclay GR, Fleming SC: Intraoperative oesophageal Doppler guided fluid management shortens postoperative hospital stay after major bowel surgery. Br J Anaesth 2005, 95:634642.

53. Venn R, Steele A, Richardson P, Poloniecki J, Grounds M, Newman P: Randomized controlled trial to investigate the influence of the fluid challenge on duration of hospital stay and perioperative morbidity in patients with hip fractures. $\mathrm{Br} J$ Anaesth 2002, 88:65-71.

54. Dark PM, Singer M: The validity of trans-oesophageal Doppler ultrasonography as a measure of cardiac output in critically ill adults. Intensive Care Med 2004, 30:2060-2066.

55. Singer M, Allen MJ, Webb AR, Bennett ED: Effects of alterations in left ventricular filling, contractility and systemic vascular resistance on the ascending aortic blood flow velocity waveform of normal subjects. Crit Care Med 1991, 19:11381144.

56. DiCorte CJ, Latham P, Greilich PE, Cooley MV, Grayburn PA, Jessen ME: Esophageal Doppler monitor determinations of cardiac output and preload during cardiac operations. Ann Thorac Surg 2000, 69:1782-1786.

57. Pearse R, Ikram K, Barry J: Equipment review: an appraisal of the LiDCOplus method of measuring cardiac output. Crit Care 2004, 8:190-195.

58. Wiesenack C, Prasser C, Keyl C, Rodijg G: Assessment of intrathoracic blood volume as an indicator of cardiac preload: single transpulmonary thermodilution technique versus assessment of pressure preload parameters derived from a pulmonary artery catheter. J Cardiothorac Vasc Anesth 2001, 15:584-588

59. Della Rocca G, Costa GM, Coccia C, Pompei L, Di Marco P, Pietropaoli P: Preload index: pulmonary artery occlusion pressure versus intrathoracic blood volume monitoring during lung transplantation. Anesth Analg 2002, 95:835-843.

60. Godje O, Peyerl M, Seebauer T, Lamm P, Mair H, Reichart B: Central venous pressure, pulmonary capillary wedge pressure and intrathoracic blood volumes as preload indicators in cardiac surgery patients. Eur J Cardiothorac Surg 1998, 13: 533-539.

61. Goepfert MSG, Ruter DA, Akyol DA, Lamm P, Kilger E, Goetz AE: Goal-directed fluid management reduces vasopressor and catecholamine use in cardiac surgery patients. Intensive Care Med 2007, 33:96-103.

62. Hebert PC, Wells G, Blajchman MA, Marshall J, Martin C,Pagliarello G, Tweeddale M, Schweitzer I, Yetisir E: A multicenter, randomized, controlled clinical trial of transfusion requirements in critical care. Transfusion Requirements in Critical Care Investigators, Canadian Critical Care Trials Group. N Engl J Med 1999, 340:409-417.

63. Squadrone V, Coha M, Cerutti $E$, Schellino MM, Biolino $P$ Occella P, Belloni G, Vilianis G, Fiore G, Cavallo F, Ranieri VM; Piedmont Intensive Care Units Network (PICUN): Continuous 
positive airway pressure for treatment of postoperative hypoxemia: a randomized controlled trial. JAMA 2005, 293: 589-595.

64. Lobo SM, Lobo FR, Polachini CA, Patini DS, Yamamoto AE, ed Oliveira NE, Serrano P, Sanches HS, Spegiorin MA, Queiroz MM, Christiana Jr AC, Savieiro EF, Alvarez PA, Teixeira SP, Cunrath GS: Prospective, randomized trial comparing fluids and dobutamine optimization of oxygen delivery in high-risk surgical patients [ISRCTN42445141]. Crit Care 2006, 10:R72.

65. Pearse RM, Belsey JD, Cole JN, Bennett ED: Effect of dopexamine infusion on mortality following major surgery: individual patient data meta-regression analysis of published clinical trials. Crit Care Med 2008, 36:1323-1399. 